\title{
Study on Personal and Socio-Economic Characteristics and Their Correlation with Knowledge and Adoption of Registered Flower Growers of Central Kashmir
}

\author{
Junaid Ayaz ${ }^{1}$, Noor-ul-Islam Wani ${ }^{*}$, Rahat Ashraf Wani ${ }^{2}$, \\ A.H. Hakeem ${ }^{1}$ and Tashooq Ah Bhat ${ }^{3}$
}

${ }^{1}$ Division of Agriculture Extension and Communication, ${ }^{2}$ Division of Floriculture \& Landscape Architecture, ${ }^{3}$ Division of Food Sciences and Technology, SKUAST-K, India

*Corresponding author

\section{A B S T R A C T}

\section{Key words \\ Registered flower \\ growers, Personal, Socio- economic, Knowledge, \\ Adoption and extension contacts \\ Article Info \\ Accepted: \\ 20 August 2018 \\ Available Online: \\ 10 September 2018}

The study was conducted in three districts of Kashmir valley namely Srinagar, Budgam and Ganderbal owing to the majority of registered flower growers in these three districts. Out of 300 registered flower growers, 100 registered flower growers were selected through proportional allocation method. Different personal and socio-economic characteristics of the registered flower growers were studied and their relation with knowledge and adoption was also found out. Educational qualification, land holding, income, extension contacts and risk orientation were found to be significantly correlated with knowledge and adoption of registered flower growers.

\section{Introduction}

The state of Jammu and Kashmir is endowed with ample natural resources including soil, water, topographic diversity, climatic conditions and rich natural flora which facilitate the cultivation of wide range of flowers. The total area occupied under floriculture in the state is 494 hectares. The floriculture sector generates an annual turnover of Rs 5.02 crores in the state. (Diversification through floriculture 2016) Srinagar, Budgam and Jammu are the main districts of Jammu and Kashmir having maximum area and production of lose and cut flowers. The total number of registered flower growers in state are 725 . Under greenhouse conditions the area under cut and flower in the state is 40 hectares. Srinagar, Jammu, Budgam, Ganderbalare the main district of Jammu and Kashmir having maximum area and production of loose and cut flowers. The total number of registered flower growers in Jammu and Kashmir is 725. In addition to this the area of cut and loose flowers in Jammu and Kashmir under greenhouse condition is 40 
hectares (Anonymous, 2015). The floriculture products marketed include ornamental tree species, shrubs, climbers, bulbous plants, dry flowers, cut and loose flower seeds, bulbs and essential oils. Flowers are brought to whole sale markets, which mostly operates in open yards. Few flower merchants generally buy most of produce and distribute them to local retailers. The retailer flourish shop usually operates in open on road sides. However, there are some good flourish showrooms, where flowers are kept under controlled atmospheric conditions. However, flowers are marketed to distant places through airplanes. The flowers are sold locally with predetermined and fixed rates. The prices are highly dependent on season. During the wedding seasons the products fetches maximum prices. In the absence of any regulatory mechanism, the local vendors directly purchase the flowers from the farmers, and often there is glut of flowers in the market. Thus, the price control mechanism for the same is necessarily required.

\section{Scope of study}

The present study will be useful to the policy makers and planners of the state to boost income, employment and prosperity of the farmers. The study will provide useful data to the researchers and will help them in understanding the production, marketing and transportation channels problems and constraints of the flower industry. Flowers like Carnation, Rose, Gladiolus, Gerbera, Lilium, Chrysanthemum, Marigold are the important economic crop of the growers of central Kashmir.

\section{Materials and Methods}

\section{Selection of the study area}

The three districts i.e. Srinagar, Budgam and Ganderbal of central Kashmir were purposively selected for the study since these three districts are the pioneer in the cultivation of the export quality of flowers. The survey was exhaustive in nature and the lists of registered flower growers were collected from the floriculture officers of the respective districts.

Total registered commercial flower growers in all three districts $(\mathrm{N})=300$.

\section{Selection of the respondent}

Among the registered 300 flowers growers from three districts of central Kashmir we selected 100 growers for our study. The numbers of growers in each district were selected by using the proportional allocation formula given below as:

$n_{1}=\frac{n}{N} N_{1}$

Where, $\mathrm{i}=1,2,3,4 \ldots \ldots \ldots$

$\mathrm{n}_{\mathrm{i}}=$ number of farmers to be sampled in $\mathrm{i}^{\text {th }}$ district

$\mathrm{N}_{\mathrm{i}}=$ Total number of growers in $\mathrm{i}^{\text {th }}$ district

$\mathrm{N}=$ Total number of growers in selected area

$\mathrm{n}=$ Total numbers of growers to be chosen in selected area

Hence number of samples in each district was calculated accordingly,

$n_{1}$ Sample for Srinagar district

$n_{1}=\frac{n}{N} N_{1}=\left(\frac{100}{300}\right) \times 200=66.66 \cong 66$

$n_{2}$ Sample for Budgam district

$n_{2}=\frac{n}{N} N_{2}=\left(\frac{100}{300}\right) \times 50=16.66 \cong 17$ 
$n_{3}$ Sample for Ganderbal district

$n_{3}=\frac{n}{N} N_{3}=\left(\frac{100}{300}\right) \times 50=16.66 \cong 17$

Thus, the samples drawn from three districts as per proportional allocation formula are given below:

Finally, actual respondent growers in each district were selected randomly among the above determined recognized growers in each district.

\section{Data collection}

The study is based upon both primary and secondary data gathered during the course of investigation from 2016-2017.

Construction of interview Schedule for data collection

An Interview Schedule was constructed based upon the objectives, variables and available literature on the topic. While preparing the schedule, due care was taken to avoid questions with dual meaning and contradictory statements. Before, finalization of the schedule, the survey schedule was pre-tested in the nearby areas to examine the relevance of structured questions on different aspects of production and marketing of flower crops. The schedules was modified and finalized for main survey.

\section{Primary data}

The data for the present study was collected through the survey method by personal visit. The data was collected pertaining to agricultural year 2016-17.

Commensurate with the set objectives of the study, primary data included the information on following aspects.

\section{Demographic parameters}

It included age, education, family type/ income, etc of the respondents.

\section{Farm production system}

It included the data on yield of flower crops, farm prices, etc.

\section{Marketing aspects}

It included marketing pattern and practices followed by sampled growers and traders. Disposal pattern of flowers through different functionaries and marketing costs borne by the functionaries

\section{Transportation aspects}

It includes data on transportation pattern regarding local market or through distant market.

\section{Problem and constraints}

It included data on production, marketing and finance and transportation problems.

\section{Secondary data}

Secondary data on area, production, prices and arrivals of different flower commodities in the markets were collected from the directorate of floriculture. In addition, various published/ unpublished sources and official websites of department of floriculture have been used the collection of secondary data. (Directorate of Floriculture)

\section{Pre-testing of interview schedule}

Before finalization of the interview schedule, it was pre-tested by interviewing ten members who were not included in the sample in order to know whether the respondents can furnish 
the required information and whether the questions were clear and can be easily understood by the respondent.

\section{Results and Discussion}

Personal and socio-economic characteristics of registered flower growers, and their relationship with knowledge and adoption

Age

Age is one of the important basic characteristic of an individual. Age was operationalized as the chronological age of the registered flower growers completed in years at the time of investigation. It is clear from Table that in district Srinagar, 71.21 per cent of the registered flower growers belonged to middle age category followed by old age category 15.16 per cent and young age category 13.63 per cent.

In district Budgam 82.35 per cent of the registered flower growers belonged to middle age category followed by old age category 17.65 per cent and young age 0 per cent. In district Ganderbal, 58.82 per cent of the registered flower growers belonged to middle age category followed old age category 29.41 per cent and by young age 11.77 per cent.

Statistically there was a non-significant relationship between age and knowledge $(\mathrm{r}=0.250)$ and relationship between age and adoption $(\mathrm{r}=0.255)$ was also found nonsignificant in all the three districts.

This might be due to the fact that age influences the registered flower growers' interest in knowing the new things and enhances registered flower growers' curiosity about scientific ideas and new innovations and their adoption as well. Similar results were observed by Babanna (2001), Lakshmisha (2000) and Reshmy (2001).

\section{Education}

Education refers to the number of years of formal schooling obtained by the registered flower growers. The level of formal education attained by the registered flower growers tends to influence their knowledge and adoption of recommended flower Production Practices. It is evident from Table that in district Srinagar, 21.21 per cent of the registered flower growers had $10+2$ level of education while 18.18 per cent had matric qualification, 30.30 per cent of the flower growers had middle level qualification and only 6.06 per cent of the registered flower growers were illiterate. 13.64 per cent of the registered flower growers had education up to primary level. In district Budgam, it was reported that 35.29 per cent of the registered flower growers had middle level education, 29.41 per cent had matric qualification, 23.53 per cent had $10+2$ level of educational qualification and 5.88 per cent of the registered flower growers were illiterate. A minimum 5.88 per cent of the registered flower growers were graduate level. In district Ganderbal, it was reported that 29.41 per cent of the registered flower growers had middle level education, 29.41 per cent had matric qualification, 17.65 per cent had $10+2$ level of educational qualification and 17.65 per cent of the registered flower growers were illiterate.

Statistically, there was a significant relationship between education and knowledge $(\mathrm{r}=0.625)$ and also between education and adoption $(r=0.607)$ of the registered flower growers. This is due to the fact that education brings about desirable changes in an individual's knowledge, attitude and skill. Higher the education, higher is the knowledge and adoption of recommended flower production practices. It seems that comparatively higher education level of registered flower growers must have enabled them to make use of relevant literature and might have better contacts with extension 
agency. Similar results were also reported by Balasubramani (1997) and Yogananda (1992).

\section{Family type}

Family is a group of closely related persons living together in a single household with a common kitchen. Family size refers to the total number of individuals having blood relations and living in one family. It is evident from table in district Srinagar, 50 per cent of the registered flower growers had joint family size and about 50 per cent of registered flower growers had nuclear family size. In district Budgam, 64.71 per cent of the registered flower growers had joint family size and above 35.29 per cent of registered flower growers had nuclear family size.In district Ganderbal, 59.82 per cent of the registered flower growers had joint family size while 41.18 per cent of the registered flower growers had nuclear family size.

Statistically, there was a non-significant relationship between family size and knowledge $(\mathrm{r}=0.048)$ and non-significant relationship was observed between family size and adoption ( $r=0.059)$. Thus, with the large size family, the registered flower growers would be interested in making flower production profitable. The findings are in conformity with the findings of Lakshmisha (2000) and Vedamurthy (2002).

\section{Annual income}

In the present study, the term annual income refers to the total income generated by an individual in a year by all the known sources of income in the family. It was observed from analysis of the data as shown in table that in district Srinagar, 60.61 per cent of the registered flower growers had medium income Rs 2-4 lakh whereas, 39.39 per cent of the registered flower growers had low income of up to Rs 2 lakh followed by 0 per cent of registered flower growers had high income of Rs 4 lakh and above. It was observed from analysis of the data as shown in table that in district Budgam, 94.12per cent of the registered flower growers had medium income Rs 2-4 lakh whereas, none of the registered flower growers had low income of up to Rs 2 lakh only 5.88 per cent of registered flower growers had high income of Rs 4 lakh and above. It was observed from analysis of the data as shown in table that in district Ganderbal, 88.24 per cent of the registered flower growers had medium income Rs 2-4 lakh whereas, 11.76 per cent of the registered flower growers had low income of up to Rs 2 lakh and none of registered flower growers had high income of above Rs 4 lakh.

Statistically, there was a significant relationship between annual income and knowledge $(r=0.899)$ and also a significant relationship between annual income and adoption $(r=0.829)$. The reason may be that the high income registered flower growers can purchase costly agricultural inputs and implements. Similarly, they have no problem of getting loans and subsidies because of high economic status in the society and develop better contacts with outside world. It also enables registered flower growers to take risk in trying new ideas regarding flower production. Thus, annual income is a vital index of social status. The results are in conformity with the results of Balasubramani (1997) and Vedamurthy (2002).

\section{Land holding}

The size of the land holding refers to the number of hectares of land owned by a registered flower grower. In the present study, Table 1 revealed that in district Srinagar, a majority 92.42 per cent of the registered flower growers had small land holding up to10 kanal followed by 7.58 per cent having medium land holding 10-20 kanal. 


\section{Selection of the study area}

\section{District}

Total registered flower growers

\section{Srinagar}

200
Budgam

50
Ganderbal

50

The samples drawn from three districts as per proportional allocation formula

\begin{tabular}{|l|c|c|c|c|}
\hline Districts & Srinagar & Budgam & Ganderbal & Total \\
\hline Samples to be drawn & 66 & 17 & 17 & 100 \\
\hline
\end{tabular}

Correlation coefficient between socioeconomic characteristics and knowledge

\begin{tabular}{|l|l|l|}
\hline S. No & Socioeconomic characteristics & p-valve \\
\hline 1 & Age & 0.250 \\
\hline 2 & Education & $0.625^{*}$ \\
\hline 3 & Experience & $0.788^{*}$ \\
\hline 4 & Land Holding & $0.774^{*}$ \\
\hline 5 & Income & $0.899^{*}$ \\
\hline 6 & Extension Contacts & $0.505^{*}$ \\
\hline 7 & Innovative Proneness & 0.444 \\
\hline 8 & Risk Orientation & $0.613^{*}$ \\
\hline 9 & Family Type & 0.048 \\
\hline
\end{tabular}

* Positively significant towards knowledge.

Correlation coefficient between socioeconomic characteristics and Adoption

\begin{tabular}{|l|l|l|}
\hline S. No & Socioeconomic characteristics & p- valve \\
\hline $\mathbf{1}$ & Age & 0.255 \\
\hline $\mathbf{2}$ & Education & $0.607^{*}$ \\
\hline $\mathbf{3}$ & Experience & $0.888^{*}$ \\
\hline $\mathbf{4}$ & Land Holding & $0.684^{*}$ \\
\hline $\mathbf{5}$ & Income & $0.829 *$ \\
\hline $\mathbf{6}$ & Extension Contacts & $0.525^{*}$ \\
\hline $\mathbf{7}$ & Innovative Proneness & 0.340 \\
\hline $\mathbf{8}$ & Risk Orientation & $0.665^{*}$ \\
\hline 9 & Family Type & 0.059 \\
\hline
\end{tabular}

* Positively significant towards Adoption 
Table.1 Personal and socio-economic characteristics of registered flower growers

$(\mathrm{N}=100)$

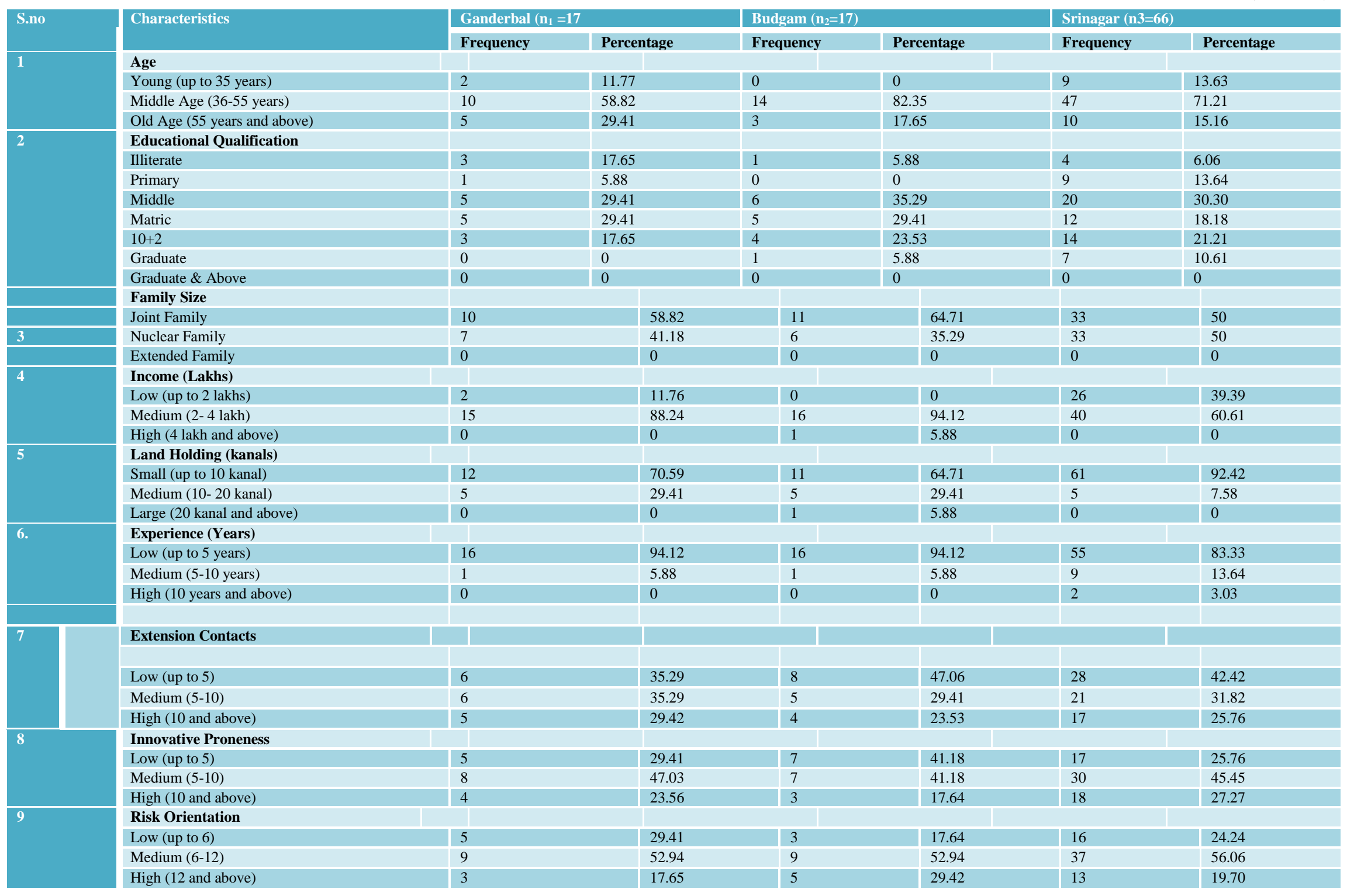


In district Budgam, a majority of the registered flower 64.71 per cent had small land holding (upto10 kanal) while as29.41 per cent had medium land holding 10-20 kanal, followed by 5.88 per cent of the registered flower growers having large land holding Above 20 kanal. In district Ganderbal, a majority of the registered flower growers 70.59 per cent had small land holding (upto10 kanal) while as 29.41 per cent had medium land holding (10-20 kanal).

Statistically there was a significant relationship between land holding and knowledge $(r=0.774)$ while as relationship between land holding and adoption was also significant $(r=0.684)$. The possible reason that could be attributed was that more the land holding, more is the enthusiasm to adopt the recommended flower production practices. The findings are in the line with the findings of Saravana Kumar (1996), Raut (1985) and Borude (1992).

\section{Experience in flower growing}

Experience in flower growing means the number of years over which the registered flower grower has been cultivating flowers. Experience in flower growing is calculated in years. The figure in table 1 indicate that in district Srinagar83.33per cent of the registered flower growers had low experience in flower growing up to 5 years, while as 13.64 per cent of the registered flower growers had medium experience in flower growing 5-10 years.

A small percentage 3.03 per cent of the registered flower growers had high experience in flower growing 10 years and above. In district Budgam, a majority of the registered flower growers 94.12 per cent had low experience in flower growing up to 5 years followed by 5.88 per cent having medium experience 5-10 years and none of the registered flower growers had having experience of 10 years and above. In district Ganderbal also, a majority of the registered flower growers 94.12 per cent had low experience in flower growing up to 5 years followed by 5.88 per cent having medium experience 5-10 years and none of the registered flower growers had an experience of and 10 year and above.

Statistically, there was a significant relationship between experience in flower growing and knowledge $(\mathrm{r}=0.788)$ and also between experience in flower growing and adoption $(\mathrm{r}=0.888)$ of the registered flower growers. This may be due to the fact that the experience lessens the extent of problems and helps in more adoption of the recommended flower production practices as it influences the knowledge and skills of the registered flower growers for better adoption. The findings are in conformity with the findings of Borude (1992) and Vedamurthy (2002).

\section{Extension contacts}

The Extension contacts refer to the number of persons contacted by the registered flower grower for obtaining information regarding flower production. Data in Table 1 reveals that in District Srinagar more than 42.42 per cent of the registered flower growers had low extension contacts whereas, 31.82 per cent of the registered flower growers had medium contacts and 25.76 per cent of the registered flower growers had high extension contacts. In district Budgam, a majority of the registered flower growers 47.06 per cent had low extension contacts. While as, 29.41 per cent and 23.53 per cent of the registered flower growers had medium and high extension contacts respectively. In district Ganderbal, 35.29 per cent of the registered flower growers had low extension contacts and the equal percentage 35.29 per cent had medium extension contacts. While as 29.42 per cent of the registered flower growers had high extension contacts.

Statistically, there was a significant relationship between Extension contacts and knowledge $(\mathrm{r}=0.505)$ and also significant relationship between extension contacts and adoption $(r=0.525)$ of the registered flower growers. The similar findings were observed by Babanna (2002) and Kumaran (2004). 


\section{Innovative proneness}

It was noticed in Table 1 that in District Srinagar more than 45.45 per cent of the registered flower growers had medium innovative proneness whereas, 27.27 per cent of the registered flower growers had high innovative proneness and 25.76 per cent of the registered flower growers had low innovative proneness. In district Budgam, a majority of the registered flower growers 41.18 per cent had low extension contacts and an equal percentage 41.18 per cent had medium level of innovative proneness and 17.65 per cent of the registered flower growers had high innovative proneness. In district Ganderbal, 29.41 per cent of the registered flower growers had low extension contacts and 47.03 per cent of the registered flower growers had medium level of innovative proneness. While as 23.56 per cent of the registered flower growers had high level of innovative proneness.

Statistically, there was a non- significant relationship between Innovative proneness and knowledge $(r=0.444)$ and also non-significant relationship between innovative proneness and adoption $(\mathrm{r}=0.340)$ of the registered flower growers. These findings were in confirmation with Babanna (2001).

\section{Risk orientation}

It was noticed in Table 1 that in District Srinagar more than 24.24 per cent of the registered flower growers had low risk orientation whereas, 56.06 per cent of the registered flower growers had medium risk orientation and 19.70 per cent of the registered flower growers had high risk orientation. In district Budgam, a majority of the registered flower growers 17.64 per cent had low risk orientation and 52.94 per cent of the registered flower growers had medium level of risk orientation followed by 29.42 per cent of the registered flower growers had high risk orientation. In district Ganderbal, 29.41 per cent of the registered flower growers had low extension contacts and 52.94 per cent of the registered flower growers had medium level of risk orientation. While as, 17.65 per cent of the registered flower growers had high level of risk orientation.

Statistically, there was a significant relationship between risk orientation and knowledge $(\mathrm{r}=0.613)$ and also significant relationship between risk orientation and adoption $(\mathrm{r}=0.665)$ of the registered flower growers. The findings were in agreement with the results of the study reported by Awasthi et al., (2000), Balasubramaniam et al., (2001).

The majority of registered flower growers 71.21 per cent were of middle age group 35-55 years, whereas 15.16 per cent were of old age group above 55 years, followed by 13.63 per cent were of young age group up to 35 years respectively. Only 30.30 per cent of registered flower growers were having an education of middle level, whereas 21.21 per cent had an education level of $10+2$, followed by matric, primary, graduate and illiterate. (18.18, 13.64, 10.61 and $6.06 \%$ ) per cent respectively. Equal numbers of registered flower growers were having a family type of joint and nuclear family. None of registered flower growers had an annual income of above Rs 4 lakh while as 60.61 per cent of registered flower growers had annual income ranges from Rs 2-4 lakh, while as 39.39 per cent of registered flower growers had an annual income of Rs 2 lakh. More than 92.42 per cent of registered flower growers had a land holding up to 10 kanal. Whereas, 7.58 per cent of registered flower growers up to 1020 kanal. Majority of registered flower growers 83.33 per cent had low experience up to 5 years, while as 13.64 per cent of registered flower growers had medium experience up to 5 to 10 years, followed by 3.03 per cent had high experience above 10 years. Only 42.42 per cent of registered flower growers were having low extension contacts, whereas 31.82 per cent had medium extension contracts followed by 25.76 per cent of registered flower growers had high extension contracts. Only 45.45 per cent of registered flower growers had medium innovative proneness, while as 27.27 per cent 
had high innovative proneness followed by 25.76 per cent of registered flower growers had low innovative proneness. Majority of 56.06 per cent the registered flower growers had had medium risk orientation, whereas 24.24 per cent had low followed by 19.70 percent of registered flower growers had high risk orientation.

\section{References}

Anonymous, 2015. Present Status and Prospects of Floriculture in Jammu and Kashmir, ICAR Directorate of Floriculture Research Pune-411005 (Maharashtra), pp. 22-40.

Awasthi, H. K., Singh, P. R. and Sharma, R. N. 2000. Knowledge and attitude of dairy farmers towards improved dairy practices. Maharashtra Journal Extension Education 19: 290-292.

Babanna, T. 2002. Information source consultancy and training needs of farmers in arecanut cultivation under Tungabhadra command area in Shimoga district. M. Sc. (Agri.) Thesis, University of Agricultural Sciences, Bangalore.

Balasubramani, N. 1997. Knowledge and adoption behavior of rubber growers in Belthangadi taluk of Dakshina Kannada district. M. Sc. (Agri.) Thesis, University of Agricultural Sciences, Bangalore.

Borude, S. V. 1992. An impact of Dairy Cooperative Society on Socio-economic Development of Member Farmers. Thesis submitted to Mahatma Phule Krishi Vidyapeeth, Rahuri, Maharashtra State.

Kumaran, M. Ponnusamy, K. and Krishnan, M., 2004. Utilization of information sources by shrimp farmers. Indian journal of
Extension Education, 40(1-2): 63-66.

Lakshmisha, 2000. Impact of Cashew demonstration on Knowledge and adoption and yield levels farmers in Dakshina Kannanda district. M. Sc. Thesis submitted to university of Agricultural sciences, Bangalore, Karnataka, India.

Raut, D. R. 1985. A study of the member farmers of Parvara Sahkari Doodh Vyavasyik Santha of Ahmadnagar District and Problem faced by them in Dairy Occupation M. Sc. Thesis submitted to Mahatma Phule Krishi Vidyapeeth, Rahuri, Maharashtra State.

Reshmy, C. 2001. A study on sustainability of coconut and banana intercropping in Kerla - An analysis. M. Sc. Thesis submitted to university of Agricultural Sciences, Banglore, Karnataka, India.

Saravana Kumar, R., 1996. A study on management of mango gardens by farmers in Krishnagiri taluk of Dharmapouri district, Tamil Nadu. MSc. (Agri.) Thesis, University of Agricultural Sciences, Dharwad.

Vedamurthy, H. S., 2002. A study on the management of Areca Gardens and marketing pattern preferred by the Areca nut growers of Shimoga district in Karnataka. M. Sc. Thesis submitted to university of Agricultural sciences, Bangalore, Karnataka, India.

Yogananda, H. G. 1992. A study on knowledge level, adoption behaviour and training needs of coconut growers. M. Sc. Thesis submitted to university of Agricultural sciences, Bangalore, Karnataka, India.

\section{How to cite this article:}

Junaid Ayaz, Noor-ul-Islam Wani, Rahat Ashraf Wani, A.H. Hakeem and Tashooq Ah Bhat. 2018. Study on Personal and Socio-Economic Characteristics and Their Correlation with Knowledge and Adoption of Registered Flower Growers of Central Kashmir. Int.J.Curr.Microbiol.App.Sci. 7(09): 2891-2900. doi: https://doi.org/10.20546/ijcmas.2018.709.359 